\title{
Are Transfer Students Different? An Examination of First-Year Grades and Course Withdrawals
}

Jo Stewart and Felice Martinello

Brock University

\begin{abstract}
Using data from several introductory-level courses at one Canadian university, community college transfer students were compared to transfer students from other universities and to non-transfer students on a number of measures of academic success. The three groups did not differ significantly in terms of course withdrawal rates, and final course grades for college transfer students were not significantly different from those of non-transfer students. However, students who had transferred from other universities received higher final grades. Mid-course grades and gender comparisons are discussed, as are policy implications and suggestions for future research.

\section{RÉSUMÉ}

Au moyen de données provenant de plusieurs cours d'introduction dispensés dans une université canadienne, des mesures de réussite académique ont été comparées entre des étudiants de collèges communautaires provenant de différentes institutions académiques, ainsi qu'avec des étudiants qui ne sont pas en transfert. Les trois groupes ne présentaient pas de différences substantielles entre eux en ce qui concerne les taux d'abandon de cours. En outre, les notes finales des étudiants provenant d'autres universités ne présentaient pas de différences notables devant celles des étudiants qui n'étaient pas en transfert. Cependant, les étudiants provenant d'autres universités ont obtenu des notes finales plus élevées que les étudiants qui n'étaient pas en transfert. L'article aborde les résultats de mi-parcours et compare ceux-ci entre les hommes et les femmes; on y présente également les incidences politiques et des suggestions pour de futures recherches.
\end{abstract}


A consistent theme in post-secondary education is the importance of facilitating seamless student transfers between different types of institutions. Considerable research has investigated students who transfer from two-year colleges to four-year institutions and the academic consequences of their transfer decisions, including studies on the reasons for transfer (Andres, 1999), perspectives and experiences of students (Andres, 2001), demographic characteristics of this group (Lee \& Frank, 1990; Wattamaniuk, 2010), transfer rates (Bers, 2007), the rate of attainment of a baccalaureate degree (Townsend, 2007), and grade point average (GPA) (Hills, 1965). Although the results are mixed, researchers noticed very early on that transfer students differed on a number of these measures from students who began their studies at four-year institutions.

The term transfer shock was first used by Hills (1965) as a global term to describe the drop in grade point average (GPA) experienced by students in the United States who transferred from two-year community colleges to four-year degree-granting institutions. Research shows that the drop in GPA may be related to a variety of student characteristics including demographic variables such as socio-economic status, race, and gender (Lee \& Frank, 1990; Sheldon, 2009), psychological barriers and challenges such as motivation and self-concept (Wang, 2009), anxiety and stress (Andres, 2001; Andres, Qayyum, \& Dawson, 1997), social factors (Lee, Mackie-Lewis, \& Marks, 1993), economic and family concerns (Nora, Cabrera, Hagedon, \& Pascarella, 1996), and academic preparation for university (Reason, 2003). Other possible reasons for transfer shock include a variety of college and university experiences such as adjustment to new educational settings and social groups (Berger \& Malaney, 2003). Townsend (2001) is also concerned with the quality of education offered at community colleges. She states that "the drop in GPA may reflect institutional differences in standards or expectations for academic performance as well as insufficient preparation for upper-division courses" (p. 37).

Transfer shock is a concern to degree-granting institutions because of its effect on student success. Transfer shock may contribute to course failures that result in students taking longer to complete their degrees (Thurmond, 2007) and affect students' persistence and retention. It has been noted that the lower GPA for transfer students in their first year at university tends to correct itself in subsequent years (Lambert-Maberly, 2010; Nolan \& Hall, 1978). However, it is not clear whether the increased transfer student GPA in subsequent years is due to the withdrawal of failing transfer students after first year or to a true rise in the average GPA.

Much of the existing research focuses on the experiences of transfer students in the United States. Bell (1998) noted a paucity of research on the characteristics and outcomes of transfer students in Canada, but the Canadian literature has expanded since Bell's time of writing with a report on college transfer students at York University (College University Consortium Council, 2008) and a report on college student transfer success at Nipissing University (College University Consortium Council, 2007), along with other works cited here. Research on Canadian transfer students, however, is complicated by differences across provinces in the transfer system between community colleges and universities. For example, in British Columbia transfer arrangements are clearly articulated for students who wish to complete a four-year degree by studying for two years at a community college and then completing their studies at a university. The British Columbia Council on Admissions and Transfer (BCCAT) has conducted extensive research on the success of transfer students in that province. BCCAT has found that most transfer students ex- 
perience a drop in GPA (Lambert-Maberly, 2010) and that many students find this drop anxiety-provoking (Andres, 2001; Andres, Qayyum, \& Dawson, 1997). British Columbia researchers have also found that many transfer students do raise their GPA from admission to completion of their degree programs (Lambert-Maberly, 2010).

British Columbia's transfer system is similar to that of Alberta. Transfer students in Alberta reportedly also "do not perform as well as direct entry students" (cited by Bell, 1998, University of Calgary, 1995, p. 2).

Ontario does not have a tradition of seamless transfer between community colleges and universities. In high school, Ontario students are streamed into college or university preparatory courses, and the one-, two-, or three-year certificate or diploma programs offered by Ontario Colleges of Applied Arts and Technology were historically designed as terminal educational credentials, providing students with training necessary to enter the workforce rather than as paths to university degrees. As a result, and in contrast to students in the United States and other Canadian provinces, Ontario students generally cannot easily transfer their college credits to university, though some transfer arrangements have been made for community college programs, such as nursing or business, with a "high affinity" to university programs in the same professions. It is not uncommon for Ontario students who have successfully completed two or three years at a community college to be granted less than a full year's academic credit at university. Thus most Ontario college transfer students must start their university studies with first-year and not upper-year courses, and completion of a "four-year" degree may require a total of five to six years of post-secondary study after their start in college.

Bell (1998) found that college transfer students at one Ontario university had higher GPAs than non-transfer students at the end of their first year at the university, but then, surprisingly, they had a much lower graduation rate than non-transfer students. A study of a collaborative nursing program in Ontario showed results similar to those found in the United States (Cameron, 2005). In this program, students begin their studies at a community college and complete their degrees at a university. The students are aware of this transfer from the beginning. The program curriculum is jointly developed and coordinated by the college and the university, ensuring that the transfer is as seamless as possible. However, Cameron discovered that $64.8 \%$ of her sample reported that their GPA decreased in the first semester at university, while only $7.4 \%$ indicated that their grades increased.

Cameron's research is similar to much of the literature on college-to-university transfer students. It focuses on tracking students' performance from one institution to another. However, examining the change or drop in GPA from college to university is problematic because of the difficulty in determining whether the grading standards at the two institutions are comparable. That is to say, a large drop in GPA may be the result of high college grades rather than low university grades (as suggested by Townsend, 2001), thus any change in GPA may be a relatively unreliable measure of how well or poorly a transfer student is actually doing in university. Although anecdotal evidence from advisers and professors, and empirical studies comparing college and first-year university GPAs (e.g., Cameron, 2005), suggests that college transfer students do not perform as well as non-transfer students in first-year classes, it is not clear whether the drop in GPA for transfer students is typical of all students in their first year at university, or if the transfer shock phenomenon is systematically different from the transition difficulties that non-transfer university students experience. 
Recall that transfer shock is studied and considered important because of its relation to transfer students' performance in their new institutions, and the consequent effects on their persistence in university, degree completion, and time to degree. Given that impact, and the difficulties with the concept of transfer shock articulated above, we focused on what we believe is the main issue of concern: namely, the performance and progress of transfer students in their new institution, rather than the change in their grades from the grades they received at their old institution. Specifically, we compared outcomes for college transfer students with outcomes for non-transfer students in a sample of two-term, first-year classes completed by both groups. To ensure that any results were specific to students transferring from a community college, we also examined outcomes for students who transferred from other four-year universities in those same courses.

Students' performance and progress in post-secondary education is multidimensional and, we contend, not well captured by a single measure such as final course grades. Thus, in addition to final course grades, we examined differences in the likelihoods that students withdrew from the courses before completion with no grade assigned. Withdrawals do not provide a precise (inverse) measure of retention or academic progress because students who withdraw from a course may enrol in other courses in the next term to complete their degrees. However, there is no doubt that withdrawals from courses are negatively related to overall persistence and academic progress at university. For example, Adelman wrote that "one of the most degree-crippling features of undergraduate histories is an excessive volume of courses from which the student withdrew without penalty" (2006, p. 8). Further, this measure helps address the concern of some researchers that transfer students may take longer than non-transfer students to complete their studies (e.g., Thurmond, 2007).

Finally, we also consider differences in the dynamics of students' progress through their courses by examining the likelihood that students failed the first term of their courses. For those who did fail the first term, we studied the improvement in grades from midyear to the final course grade. To our knowledge, there is no other work in the Canadian or American literature examining these other aspects of transfer students' performance .

The study is relevant for determining how best to support college transfer students enrolled at university to maximize their academic development and success, and for guiding college, university, and government resource allocation. The research also has significant policy implications for universities and their governing bodies regarding the development, continuation, and possible enhancement of policies facilitating college-university student transfers.

\section{METHOD}

\section{Institutional Setting}

The data were collected during the 2008-2009 academic year at Brock University, a four-year university in southern Ontario that offers master's education in most fields and several doctoral programs. Brock is a mid-sized university with approximately 17,000 undergraduate and 1,400 graduate students in six faculties (Applied Health Sciences, Business, Education, Humanities, Mathematics and Science, and Social Sciences). Students usually declare a major in a discipline in one of the faculties; Combined Major students 
declare a major in two fields of study within a faculty or across faculties. There are two categories of students without a major: General Studies and Undeclared. Recent academic regulation changes enable students in good academic standing to remain without a major and graduate with a General Studies degree. The remaining students without a major are classified as Undeclared. These students include those adjudicated out of their chosen major because of poor academic performance and those admitted before the academic regulation changes who would now be classified as General Studies. Undeclared students are in transition; to graduate, they must complete the requirements for a degree with a major area of study or a General Studies degree.

The data were collected from administrative records on all students enrolled in a sample of first-year undergraduate social science courses. All of the courses required 24 weeks of lectures (with at least three lecture hours a week) over the fall 2008 and winter 2009 terms and provided students with one academic credit. A standard full course load for students at Brock University is five academic credits taken over the fall and winter terms; an honours bachelor's degree requires 20 academic credits. Students may withdraw from a course without academic penalty within the first 16 weeks of lectures in one-credit courses. If they do not withdraw during this period, they must be assigned a final grade.

Academic regulations at Brock require that each undergraduate take three first-year context credits, one in each of the Faculties of Humanities, Mathematics and Science, and Social Sciences. Consequently, all the introductory-level courses in the social sciences in our sample included both students majoring in that discipline and students majoring in another discipline who were taking the course as an elective or to satisfy a context requirement. As well, substantial numbers of upper-year, non-major students were enrolled in these first-year courses.

\section{The Sample}

The data set consists of a sample of 3,636 students who remained enrolled in at least one of 11 courses after the initial two-week add/drop registration period. ${ }^{1}$ Three courses (CHYS 1F90, PSYC 1F90, and SOCI 1F90) had multiple sections, with at least one section offered in the late afternoon or evening. For each of these courses, observations were combined across sections. Many students were enrolled in more than one of the courses, so they occur more than once in the sample. Altogether, the data set contains observations on 5,640 student-courses.

The data identify two kinds of transfer students: students who transferred to Brock from a community college and those who transferred to Brock from another university before 2008-2009. Students were identified as transfer students if they had completed any post-secondary work elsewhere that resulted in at least a half-credit transfer to Brock before 2008-2009 and before attending Brock; 261 of the students in the data set are transfers from community colleges, while 92 are transfers from other universities. They account for 346 and 119 of the observations on student-courses, respectively.

\section{Measures}

The data include final course grade, whether students withdrew from the course without academic penalty, and students' mid-year grades if they received a failing grade in the first term of the course. These data were used to construct a dummy variable (Failed First Term) 
that equalled one if the student failed first term of the course and zero otherwise. They were also used to construct a variable (Improved) which shows the increase in the final grade compared with the failed first term grade of the course. Dummy variables that equal one if true and zero if false were also created to indicate the student's faculty and course.

Most of the students in the sample are in their first year of university, but, as noted above, many upper-year students are also enrolled in the courses. It is important to control for the number of credits already completed because upper-year students, with greater experience in university courses, are likely to score higher grades in the first-year courses considered here. The data contain indicators of the approximate number of credits students completed before 2008-2009 (o, 0.5 to 5, 5.5 to 10, and over 10), but the data are imperfect in that they assign zero previous credits to some students who have previously completed credits. It would be very difficult to correct those errors. We believe, however, that it is worthwhile to retain and use even approximate information on number of previous credits. Fortunately, as will be shown below, inclusion or exclusion of the previous credits variables makes no difference to inferences about the performance of transfer students or any of the other variables, though the goodness of fit of the regressions is reduced if the variables related to previous credits are excluded.

A variable showing students' gender is included in the data set, but other variables often included in analyses of student performance are not available. These variables include other personal characteristics (e.g., age, race, ethnicity, family status, visa student or recent immigrant, part time or full time), family background (e.g., parents' income or occupations), and academic performance in their previous academic institution (college, university, or high school).

\section{RESULTS}

\section{Characteristics of Transfer and Non-Transfer Students}

Table 1 shows some of the characteristics of the two types of transfer students compared with non-transfer students. Approximately two-thirds of non-transfer students are women, and the proportion is virtually the same for college transfer students. A smaller proportion of transfer students from universities are women (55.4\%), but the differences between this group and college transfer or non-transfer students are not statistically significant.2

The middle panel of Table 1 shows the distribution of the three groups of students across the faculties at Brock. Considering only statistically significant differences (at the $5 \%$ level), transfer students from colleges are less likely to be in the Faculty of Education and more likely to be majoring in the Faculty of Social Sciences than non-transfer students. University transfer students are more likely to be General Studies students or in the Faculty of Mathematics and Sciences. 3

The bottom panel of Table 1 shows the distribution of student-courses across the 11 courses included in our sample. Most of the differences were not statistically significant, but university transfer students are more likely to have enrolled in Human Geography than non-transfer students. Table 1 shows other differences across faculties and courses, including some statistically significant at the $10 \%$ level.

Table 2 shows the means, standard deviations, and number of observations for the variables used in the comparisons of means (Table 3) and the regression analysis (Tables 
Table 1.

Characteristics of Non-Transfer, College Transfer, and University Transfer Students

\begin{tabular}{|c|c|c|c|}
\hline Percentage of Students & Non-Transfer & $\begin{array}{c}\text { Transfer from } \\
\text { College }\end{array}$ & $\begin{array}{c}\text { Transfer from } \\
\text { University }\end{array}$ \\
\hline \multicolumn{4}{|l|}{ Gender } \\
\hline Male & 37.23 & 37.04 & 44.57 \\
\hline Female & 62.77 & 62.96 & 55.43 \\
\hline \multicolumn{4}{|l|}{ Faculty } \\
\hline Applied Health Sciences & $15 \cdot 90$ & 18.52 & 9.78 \\
\hline Business & 2.52 & 2.31 & 1.09 \\
\hline Combined Major & 0.51 & 0.00 & 1.09 \\
\hline Education & 6.07 & $1.39^{\mathrm{a}}$ & 2.17 \\
\hline General Studies & 10.34 & 9.72 & $20.65^{\mathrm{a}}$ \\
\hline Humanities & $14 \cdot 36$ & 11.57 & 14.13 \\
\hline Mathematics and Science & 2.55 & 2.78 & $7 \cdot 61^{\mathrm{a}}$ \\
\hline Social Sciences & 30.47 & $40.74^{\mathrm{a}}$ & 33.70 \\
\hline Undeclared & 17.28 & 12.96 & $9.78^{c}$ \\
\hline Total & 100.00 & 100.00 & 100.00 \\
\hline \multicolumn{4}{|c|}{ Percentage of Student-Courses } \\
\hline \multicolumn{4}{|l|}{$\underline{\text { Courses }}$} \\
\hline Child and Youth Studies & 10.67 & 13.01 & 10.08 \\
\hline Communication Studies & $5 \cdot 51$ & 4.05 & $7 \cdot 56$ \\
\hline Film Studies & 6.42 & $4 \cdot 34$ & 8.40 \\
\hline Human Geography & 8.48 & 6.94 & $14.29^{\mathrm{b}}$ \\
\hline Physical Geography & 8.19 & 9.54 & $12.61^{\mathrm{c}}$ \\
\hline Labour Studies & 2.55 & 2.02 & 1.68 \\
\hline Popular Culture & 3.25 & 2.31 & 0.84 \\
\hline Political Science & 8.25 & $5 \cdot 49^{c}$ & 6.72 \\
\hline Psychology & 21.95 & 24.28 & 15.97 \\
\hline Sociology & 19.94 & 21.97 & $13.45^{\mathrm{c}}$ \\
\hline Women's Studies & 4.79 & 6.07 & $8.40^{c}$ \\
\hline Total & 100.00 & 100.00 & 100.00 \\
\hline
\end{tabular}

Note: ${ }^{\mathrm{a}}$, ${ }^{\mathrm{b}}$, and ${ }^{\mathrm{c}}$ indicate significantly different from non-transfer students at the 1,5 , and 10\% levels, respectively.

4 and 5), calculated over the student-course observations. All of the variables except Final Course Grade and Improved are dummy variables. Final Course Grade is the final grade for the course out of a possible maximum of 100 marks. There are only 5,103 observations on Final Course Grade because, as the second row shows, students withdrew from 8.09\% of the 5,640 student-courses in the data set and, therefore, did not receive final grades.4

The third row of Table 2 shows that Failed First Terms occurred in over $21 \%$ of the student-courses in the data set. Some students withdraw from courses when they receive failing mid-year grades, but others persevere and are assigned a final grade. The fourth 
Table 2.

Means and Standard Deviations (Calculated over the Student-Course Observations)

\begin{tabular}{|c|c|c|c|}
\hline Variable & Mean & $\begin{array}{l}\text { Standard } \\
\text { Deviation }\end{array}$ & $\begin{array}{c}\text { Number of } \\
\text { Observations }\end{array}$ \\
\hline \multicolumn{4}{|l|}{ Outcome } \\
\hline Final Course Grade & 64.10 & 14.53 & 5103 \\
\hline Withdrew & $8.09 \%$ & $27.26 \%$ & 5640 \\
\hline Failed First Term & $21.37 \%$ & $40.99 \%$ & 5640 \\
\hline Improved (final grade minus mid-year grade) & 12.82 & 11.95 & 1065 \\
\hline \multicolumn{4}{|l|}{ Transfers } \\
\hline College Transfer & $6.13 \%$ & $24.00 \%$ & 5640 \\
\hline University Transfer & $2.11 \%$ & $14 \cdot 37 \%$ & 5640 \\
\hline \multicolumn{4}{|l|}{ Gender } \\
\hline Female & $65.51 \%$ & $47 \cdot 54 \%$ & 5640 \\
\hline Male & $34.49 \%$ & $47.54 \%$ & 5640 \\
\hline \multicolumn{4}{|l|}{ Previous Credits Completed } \\
\hline $\mathrm{o}$ & $76.68 \%$ & $42.29 \%$ & 5640 \\
\hline 0.5 to 5 & $15 \cdot 51 \%$ & $36.21 \%$ & 5640 \\
\hline $5 \cdot 5$ to 10 & $4.80 \%$ & $21.39 \%$ & 5640 \\
\hline Over 10 & $4.50 \%$ & $20.74 \%$ & 5640 \\
\hline \multicolumn{4}{|l|}{ Faculty } \\
\hline Child and Youth Studies & $10.80 \%$ & $31.04 \%$ & 5640 \\
\hline Communication Studies & $5.46 \%$ & $22.72 \%$ & 5640 \\
\hline Film Studies & $6.33 \%$ & $24.35 \%$ & 5640 \\
\hline Human Geography & $8.51 \%$ & $27.91 \%$ & 5640 \\
\hline Physical Geography & $8.37 \%$ & $27.69 \%$ & 5640 \\
\hline Labour Studies & $2.50 \%$ & $15.61 \%$ & 5640 \\
\hline Popular Culture & $3.14 \%$ & $17.44 \%$ & 5640 \\
\hline Political Science & $8.05 \%$ & $27.21 \%$ & 5640 \\
\hline Psychology & $21.97 \%$ & $41.41 \%$ & 5640 \\
\hline Sociology & $19.93 \%$ & $39.95 \%$ & 5640 \\
\hline Women's Studies & $4.95 \%$ & $21.69 \%$ & 5640 \\
\hline \multicolumn{4}{|l|}{ Course } \\
\hline Applied Health Sciences & $11.72 \%$ & $32.17 \%$ & 5640 \\
\hline Undeclared & $17.02 \%$ & $37 \cdot 59 \%$ & 5640 \\
\hline Business & $1.67 \%$ & $12.80 \%$ & 5640 \\
\hline Education & $6.19 \%$ & $24.10 \%$ & 5640 \\
\hline Humanities & $11.44 \%$ & $31.83 \%$ & 5640 \\
\hline Mathematics and Science & $1.84 \%$ & $13.45 \%$ & 5640 \\
\hline Social Science & $39.27 \%$ & $48.84 \%$ & 5640 \\
\hline Combined Major & $0.50 \%$ & $7.03 \%$ & 5640 \\
\hline General Studies & $10.35 \%$ & $30.47 \%$ & 5640 \\
\hline
\end{tabular}

Note: All variables except Final Course Grade and Improved are dummy variables. 
row of Table 2 shows Improved outcomes for those who failed the first term but did not withdraw and persevered. These students earned final grades almost 13 marks higher on average than their mid-year grade.

The transfer category in Table 2 shows that $6.13 \%$ of the student-courses were taken by college transfer students while university transfer students accounted for $2.11 \%$. The gender category shows that women were enrolled in $65.51 \%$ of the student-courses in the data set. This number is slightly higher than the percentages of women shown in the top panel of Table 1 because it is calculated over the set of student-courses, whereas Table 1 refers to the percentage of students in the data set. This difference occurs because the female students in the sample are enrolled in more of the included courses than males. The next three categories in Table 2 show the distributions of student-courses by previous credits completed, faculty, and course.

\section{Comparison of Final Course Grades and Withdrawal Rates}

Table 3 shows the simple means of the various measures of student performance for transfer and non-transfer students. Final course grades for college transfer students were, on average, one mark higher than for non-transfer students, but the difference was not statistically significant. ${ }^{5}$ University transfer students, on the other hand, scored final grades more than two marks higher than non-transfer students, with the difference significant at the $10 \%$ level. The second line of Table 3 shows that both college and university transfer students were less likely to withdraw from their courses than non-transfer students, on average, but the differences were not statistically significant.

Table 3 .

Means of the Dependent Variables or Outcomes

\begin{tabular}{lccc}
\hline Variable & Non-Transfer & Transfer from College & Transfer from University \\
\hline Final Course Grade & 63.99 & 64.95 & $66.56^{\mathrm{c}}$ \\
Withdrew & $8.12 \%$ & $7.80 \%$ & $7.56 \%$ \\
Failed First Term & $21.62 \%$ & $19.65 \%$ & $15.13 \%^{\mathrm{c}}$ \\
Improved & 12.63 & $16.79^{\mathrm{a}}$ & 8.31 \\
\hline
\end{tabular}

Note: ${ }^{\mathrm{a}}$, ${ }^{\mathrm{b}}$, and ${ }^{\mathrm{c}}$ indicate significantly different from non-transfer students at the 1,5 , and $10 \%$ levels, respectively.

Simple comparisons of means, as shown in Table 3, do not control for other important variables such as number of previous credits, the course taken, or gender. Regression analysis uses these control variables to repeat the comparisons, with some omitted categories (zero previous credits, General Studies as a faculty, and Physical Geography). Transfer and non-transfer students may also differ systematically in their other personal characteristics and family background, but, as noted, data on these other characteristics are not available.

The middle columns of Table 4 show the estimated relations between the control variables and Final Course Grade and their estimated standard errors. Ordinary least squares is used to calculate the coefficient estimates and the estimated standard errors are ad- 
justed for the effects of each student's unobserved individual characteristics. ${ }^{6}$ All of the estimated standard errors in Tables 4 and 5 are similarly adjusted.

Table 4 shows that the basic inferences from Table 3 continue to hold, but they are strengthened in the regression analysis. The estimated difference in final grades between college transfer and non-transfer students remains small and statistically insignificant. ${ }^{7}$ Transfer students from other universities, however, scored final grades almost four marks higher than non-transfer students after controlling for the other variables, and the difference is statistically significant. Women's final grades were estimated to be almost three marks higher than men's, which is consistent with a large literature showing better academic performance for women than for men.

The next set of coefficients show the estimated relation between Final Course Grade and the number of previous credits held by students. Final course grades received by students with 0.5 to 10 previous credits were not significantly different from those received by students with no previous credits (the omitted category), but upper-year students with more than 10 previous credits received significantly higher grades. When the regression was re-estimated without the previous credit variables, the goodness of fit measures fell, but all of the other inferences remained unchanged. The results in Tables 4 and 5 all exhibited this robustness to the exclusion of the previous credit variables.

The estimated coefficients on the course variables show that every course has higher final grades than Physical Geography (the omitted category), on average, after adjusting for the effects of the other variables. Child and Youth Studies, Communication Studies, and Sociology have the highest final grades, while on average Physical Geography, Popular Culture, and Women's Studies have the lowest final grades.

The last set of variables shows that students with declared majors in any of the academic faculties scored higher final grades than General Studies students (the omitted category). The differences were statistically significant by wide margins. Undeclared students received even lower grades than General Studies students, while Education and Combined Major students were estimated to have the highest grades.

The two rightmost columns of Table 4 report results from a probit regression that estimates differences in the likelihoods that students withdrew from their courses. Table 4 shows that college transfer and university transfer students are not significantly different from non-transfer students in the likelihood that they withdrew from a course, on average, after adjusting for the other variables. The probabilities that males and females withdrew from a course are also estimated to be not significantly different. Students who have already completed some credits (regardless of how many more credits) are estimated to be more likely to withdraw than students who had not previously completed any credits.

There are also systematic differences across courses. All courses except Popular Culture and Women's Studies are estimated to have significantly lower probabilities of student withdrawal than Physical Geography (the omitted category). A rough analysis of the estimates shows that courses with higher grades have on average lower withdrawal rates.

Finally, compared with students in General Studies (the omitted category), students enrolled in the other faculties are less likely to withdrawal from their courses, but the differences for students in Mathematics and Science, Combined Majors, and Undeclared are not statistically significant. 
Table 4 .

Regression Coefficient Estimates for Final Course Grade and Withdrew

\begin{tabular}{|c|c|c|c|c|}
\hline \multirow[t]{2}{*}{ Variable } & \multicolumn{2}{|c|}{ Final Course Grade } & \multicolumn{2}{|c|}{ Withdrew } \\
\hline & $\begin{array}{l}\text { Estimated Regres- } \\
\text { sion Coefficient }\end{array}$ & $\begin{array}{l}\text { Estimated } \\
\text { Standard Error }\end{array}$ & $\begin{array}{l}\text { Estimated Regres- } \\
\text { sion Coefficient }\end{array}$ & $\begin{array}{l}\text { Estimated } \\
\text { Standard Error }\end{array}$ \\
\hline \multicolumn{5}{|l|}{ Transfer Students } \\
\hline College Transfer & 0.468 & 0.862 & -0.0209 & 0.1335 \\
\hline University Transfer & $3.997^{\mathrm{a}}$ & 1.524 & -0.1533 & 0.1696 \\
\hline \multicolumn{5}{|l|}{ Gender } \\
\hline Female & $2.963^{\mathrm{a}}$ & 0.481 & -0.0067 & 0.0623 \\
\hline \multicolumn{5}{|l|}{ Previous Credits Completed } \\
\hline 0.5 to 5 & -0.561 & 0.679 & $0.3273^{\mathrm{a}}$ & 0.0740 \\
\hline $5 \cdot 5$ to 10 & -0.740 & 1.141 & $0.2704^{b}$ & 0.1143 \\
\hline Over 10 & $3.187^{\mathrm{a}}$ & 0.963 & $0.2963^{b}$ & 0.1251 \\
\hline \multicolumn{5}{|l|}{ Faculty } \\
\hline Child and Youth Studies & $10.481^{\mathrm{a}}$ & 0.801 & $-0.9976^{a}$ & 0.1321 \\
\hline Communication Studies & $10.777^{\mathrm{a}}$ & 0.950 & $-0.7496^{a}$ & 0.1380 \\
\hline Film Studies & $5 \cdot 727^{\mathrm{a}}$ & 0.959 & $-0.5881^{\mathrm{a}}$ & 0.1240 \\
\hline Human Geography & $7.117^{\mathrm{a}}$ & 0.835 & $-0.6869^{a}$ & 0.1053 \\
\hline Labour Studies & $9.881^{\mathrm{a}}$ & 1.703 & $-0.3223^{b}$ & 0.1521 \\
\hline Popular Culture & $2.907^{\mathrm{b}}$ & 1.391 & -0.0418 & 0.1290 \\
\hline Political Science & $6.982^{\mathrm{a}}$ & 0.954 & $-0.7342^{\mathrm{a}}$ & 0.1199 \\
\hline Psychology & $7.285^{\mathrm{a}}$ & 0.772 & $-0.4316^{a}$ & 0.0880 \\
\hline Sociology & $10.786^{a}$ & 0.755 & $-0.7808^{a}$ & 0.0956 \\
\hline Women's Studies & $2.733^{\mathrm{b}}$ & 1.143 & -0.1735 & 0.1190 \\
\hline \multicolumn{5}{|l|}{ Course } \\
\hline Applied Health Sciences & $13.156^{\mathrm{a}}$ & 0.951 & $-0.2993^{\mathrm{a}}$ & 0.1115 \\
\hline Undeclared & $-3 \cdot 312^{\mathrm{a}}$ & 1.143 & -0.0379 & 0.0936 \\
\hline Business & $10.685^{\mathrm{a}}$ & 1.798 & $-0.4053^{b}$ & 0.1978 \\
\hline Education & $19.845^{\mathrm{a}}$ & 1.194 & $-0.8692^{\mathrm{a}}$ & 0.2847 \\
\hline Humanities & $7.177^{\mathrm{a}}$ & 1.109 & $-0.2338^{b}$ & 0.1119 \\
\hline Mathematics and Science & $14 \cdot 370^{\mathrm{a}}$ & 1.667 & -0.1911 & 0.1919 \\
\hline Social Science & $12.290^{\mathrm{a}}$ & 0.919 & $-0.3976^{\mathrm{a}}$ & 0.0923 \\
\hline Combined Major & $18.579^{a}$ & 2.071 & -0.6797 & 0.5149 \\
\hline Constant & $45 \cdot 757^{\mathrm{a}}$ & 1.121 & $-0.7202^{\mathrm{a}}$ & 0.1055 \\
\hline $\mathrm{N}$ & 5,103 & & 5,640 & \\
\hline $\mathrm{R} 2$ & 0.312 & & & \\
\hline
\end{tabular}

Notes: ${ }^{\mathrm{a}}$, ${ }^{\mathrm{b}}$, and ${ }^{\mathrm{c}}$ indicate statistically significant at the 1,5 , and $10 \%$ levels, respectively.

The Final Course Grade regression was estimated using least squares.

Probit regression was used to calculate the Withdrew estimates.

All estimated standard errors are adjusted for clustering of the error terms by student. 


\section{Transitions}

Conventional wisdom among academic advisers states that students transferring from community colleges to universities face a difficult transition during which they learn the ways university differs from college, in terms of both course content and "culture." Once they identify these differences and make adjustments, the college transfer students then improve markedly (Thurmond, 2007).

The simple averages in Table 3 provide partial support for this view. Table 3 shows that a smaller percentage of college transfer students failed the first term of the course (19.65\%) compared with non-transfer students (21.62\%), but the difference is not statistically significant. Thus one cannot conclude that college transfer students performed differently at mid-year than non-transfer students. Among those students who failed their first term, however, college transfer students improved their grades more in the second term than non-transfer students. The Improved variable shows that college transfer students' grades increased by an average of 16.79 marks, whereas increases for non-transfer students averaged only 12.63 marks, and the difference was statistically significant at the $1 \%$ level.

Table 3 also shows that a significantly lower proportion of university transfer students failed the first term of their courses compared with non-transfer students. The final grades of those who did fail improved on average by only 8.31 marks. The difference in Improved from non-transfer students is not statistically significant, however, likely because of the relatively small number of university transfer students who failed the first term.

As in the previous section, the comparisons were repeated using regression analysis so that controls for other factors could be included. Probit regression analysis was used to estimate whether transfer students were more likely to receive a failing grade in the fall term. The results are reported in the middle columns of Table 5. Controls for previous credits, course, and faculty were included in the estimation just as they were in the Table 4 regressions, but their estimated coefficients are not reported to save space. ${ }^{8}$ Table 5 confirms that transfer students from community colleges were not more likely to fail the fall term of a course than non-transfer students and that university transfer students were significantly less likely to have failed.

The rightmost columns of Table 5 show least squares regression estimates with Improved as the dependent variable. The estimates show that college transfer students who received failing first-term grades raised their final grades by almost 2.5 marks more than non-transfer students, on average and after controlling for the other factors. This finding supports the contention that college transfer students who have difficulty in their first term improve more in the second term than non-transfer students (Hills, 1965). Evidently, the better performance among college transfer students who failed first term was not sufficient to lead to a statistically significant overall higher final grade for college transfer students, compared with non-transfer students.

The regression results also indicate some interesting differences between women and men. Table 4 shows that women tend to receive higher final grades, so it is surprising that women are not significantly less likely to receive failing grades in the first term, as indicated by the middle column estimates of Table 5. The coefficient on Female is negative, suggesting that fewer women failed first term, but this difference is small and statistically insignificant. The rightmost columns of Table 5, however, show that among women who 
Table 5 .

Regression Coefficient Estimates for Failed First Term and Improved

\begin{tabular}{lcccc}
\hline Variable & \multicolumn{2}{c}{ Failed First Term } & \multicolumn{2}{c}{ Improved } \\
\hline & $\begin{array}{c}\text { Estimated } \\
\text { Regression } \\
\text { Coefficient }\end{array}$ & $\begin{array}{c}\text { Estimated } \\
\text { Standard } \\
\text { Error }\end{array}$ & $\begin{array}{c}\text { Estimated } \\
\text { Regression } \\
\text { Coefficient }\end{array}$ & $\begin{array}{c}\text { Estimated } \\
\text { Standard } \\
\text { Error }\end{array}$ \\
\hline $\begin{array}{l}\text { Transfer Students } \\
\text { College Transfer }\end{array}$ & & & & \\
$\quad$ University Transfer & -0.0728 & 0.0990 & $2.4644^{\mathrm{b}}$ & 1.2171 \\
Gender & $-0.3270^{\mathrm{b}}$ & 0.1642 & -1.9906 & 3.3944 \\
$\quad$ Female & & & & \\
Other Variables & -0.0434 & 0.0484 & $2.5096^{\mathrm{a}}$ & 0.7785 \\
$\quad$ controls for previous credits & & & & \\
controls for course & Yes & & Yes & \\
controls for faculty & Yes & & Yes & \\
$\mathrm{N}$ & Yes & & Yes & \\
$\mathrm{R}^{2}$ & 5,640 & & 1,065 & \\
\hline
\end{tabular}

Notes: ${ }^{\mathrm{a}},{ }^{\mathrm{b}}$, and ${ }^{\mathrm{c}}$ indicate statistically significant at the 1,5 , and $10 \%$ levels, respectively.

The Failed First Term regression was estimated using probit regression analysis.

Least squares was used to calculate the Improved estimates.

All estimated standard errors are adjusted for clustering of the error terms by student.

did fail the first term of a course, their final grades improved by 2.5 marks more than male students. This superior second-term performance by women who experienced difficulties in the first term likely contributed to the overall higher final course grades enjoyed by women compared with men.

\section{DISCUSSION}

The results of this study are contrary to many previous studies (see, for example, Cameron, 2005; Hills, 1965; Thurmond, 2007; Townsend, 2007) but consistent with more recent findings that community college transfer students do not differ from nontransfer students in final grades (Lambert-Maberly, 2010).

Since neither mid-year nor final grades were compared with student's previous academic achievement, the analysis provides no direct evidence of the drop in GPA upon transfer (transfer shock) that has been noted by other researchers. Nevertheless, there is indirect support for this phenomenon. To be considered for transfer to Brock University, community college students must attain a minimum $75 \%$ (B) average at college. The average final grade for college transfer students at the university was $65 \%$, indicating a drop of 10 marks. Those transfer students who failed first term very likely experienced some transfer shock, but they may also have been academically prepared to raise their grades because of their previously demonstrated academic ability. Although students chose whether to complete the course and therefore there is clearly sample selection, this "rebound effect" (noted by other researchers such as Glass \& Harrington, 2002) suggests 
that college transfer students should be encouraged to persist with their courses and apply their academic abilities to their university coursework in an attempt to raise their grades and succeed with their courses.

University transfer and non-transfer students were not significantly different in the probability of withdrawal from a course, or the difference between their mid-year and final grades if they received a failing fall-term grade. University transfer students, however, exhibited superior academic performance according to other measures. Specifically, they received higher final grades and were less likely to have failed the first term of their courses. The latter finding suggests that they may have used the experiences from previous university study to outperform their peers on those fall exams. After all, for the vast majority of the non-university transfer students, the exams at the end of the fall term would have been their first university exams and they would have had no experience preparing for or taking university-level exams.

It is not surprising that students with a declared major in an academic faculty received higher final grades than General Studies students. This result may occur because students enrolled in a major have a focus and requirements that must be met, whereas General Studies students do not have a major field of study and may lack the focus needed to see the importance of attaining higher grades. Further, students who apply to some competitive programs and do not meet the current grade cut-off are often sent an offer of admission into a General Studies stream. As a result, students accepted into a General Studies stream may have lower entry averages than those in other majors. In this case, the lower final grades for General Studies students may simply be a result of the academic characteristics of the students in that stream.

It is also not surprising that Undeclared students received lower grades in their courses than other students. Recall that most Undeclared students have been adjudicated out of a degree program because of poor academic performance in the required courses for that degree. Thus, they are likely already struggling with their coursework.

The finding that students who have already completed some credits (regardless of how many more) are much more likely to withdraw from their courses could be because students who are familiar with university rules and regulations surrounding course withdrawals are more likely to drop a course. They are also more likely to be taking the course as an elective or to satisfy a context requirement. Thus they have more freedom to withdraw from the course and enrol in an alternative than a first-year student for whom the course may be a mandatory program requirement.

Lastly, it is important to note the caveat that all of the results reported here pertain to a specific sample of courses at one Ontario university and are not necessarily generalizable to other settings.

\section{Implications and Future Research}

In this study, we found evidence that college transfer students at one Ontario university who experience difficulty in the first term of their courses but persevere are able to recover and demonstrate better academic performance in their second term than their nontransfer peers. This finding is intriguing and suggests that other universities in Ontario and across Canada may be wise to also investigate transfer student success. If findings are similar, then allocating more resources to community college transfer students to provide 
additional academic support over their first term is recommended. This approach will help students prepare for university-level work and allow them to reach their academic potential earlier. Although transfer students seem to recover from failures at a greater rate than other students, if a support network were in place to help them to avoid the failures, they may end up less frustrated. Eggleston and Laanan (2001), for example, encourage administrators to make special efforts to set up transfer student support and orientation programs to help them make the adjustments required upon transfer. If transfer students are better prepared for university, their graduating GPA may be more competitive for graduate school and professional program applications, thus allowing more successful postgraduate experiences.

Community college transfer students showed no differences in final grades or withdrawal rates from non-transfer students in the sample. This finding suggests that college to university transfers should continue to be encouraged, and that universities that implement policies to facilitate transfer from college to university will be recruiting a student group that is prepared to succeed with university-level coursework.

We have general concerns about the transfer shock phenomenon and how it is defined. Most of the research has studied the typical drop and recovery of GPA among transfer students by comparing community college grades with university grades. But, as noted in the introduction, the change in grades may reveal more about the levels of college grades than the levels of university grades and, therefore, may not provide good information about how transfer students are faring in university. Further, the decrease in grades from college to university is not compared with the change in grades for those who have entered four-year institutions directly from secondary school. Other evidence suggests that the transfer shock phenomenon exists for all students who attend university. For example, Finnie and Martinello (2010), using a sample of Canadian students, report that students' university grades are, on average, about 10 marks lower than their grades in their last year of high school. It is also conventional wisdom among academic advisers that students who attend university directly from high school experience a drop in their GPA. Future research should compare incoming averages for all students in an attempt to see if transfer shock is applicable to all first-year university students regardless of whether they enter from high school or college.

Another problem with the transfer shock literature is the singular focus on grades. A better approach, which we have adopted here, is to compare other measures of student performance such as withdrawal from courses. It is hoped that by redefining the method of examining transfer shock, researchers will examine college performance against university performance in a variety of dimensions in addition to simple GPA.*

\section{ENDNOTES}

1. The 11 courses are CHYS 1 F9o (Introduction to Child and Youth Studies), COMM 1F9o (Introduction to Communication Studies), FILM 1F94 (Introduction to Film Studies), GEOG 1F9o (Introduction to Human Geography), GEOG 1F91 (Introduction to Physical Geography), LABR 1F90 (Introduction to Labour Studies), PCUL 1F92 (Introduction to Popular Culture), POLI 1F9o (Introduction to Political Science), PSYC 1F9o (Introduction to Psychology), SOCI 1F9o (Introduction to Sociology), and WISE 1F9o (Introduction to Women's Studies). 
2. To be precise, the hypothesis tests were not done on the proportions shown in Table 1. Tests for statistically significant differences between elements in the columns of Table 1 used chi-square tests on 2 x 2 contingency tables between the occurrences (e.g., the number of women versus the number of men) for the different categories of students. The chi-square scores and $p$-values are available upon request. Proportions, rather than frequencies, are shown in Table 1 because we believe that they convey more information in an easier-to-read manner.

3. Recall that the figures shown in Table 1 are proportions of the students in our sample; namely, students enrolled in a particular set of first-year courses, and not the overall proportions for the Brock University student population.

4. Final course grade is also missing for a few other observations. These omissions occur when the student has not withdrawn from the course but is not assigned a final grade because of illness or some other special circumstances. A final course grade is usually awarded later, after the special circumstances have been resolved.

5. In Table 3, t-tests were used to test the hypothesis of no difference between the means for the non-dichotomous variables Final Course Grade and Improved. The chi-square test described in endnote 2 was used for the hypothesis tests on the dichotomous or dummy variables Withdrew and Failed First Term.

6. That is to say, the error terms in the regression are not assumed to be independently and identically distributed. Instead, the error terms corresponding to courses taken by the same student are allowed to be correlated with one another to reflect unobserved fixed effects or characteristics of the student. This adjustment is also known as an adjustment for clustering in the data.

7. In the discussions of regression results, a result or difference is significant or statistically significant when the hypothesis that the corresponding regression coefficient equals zero can be rejected at that significance level.

8. Given the results presented in Table 4, there is nothing notable about the regression coefficient estimates for the previous credits, course, and faculty dummy variables in the regressions reported in Table 5 . The full set of coefficient estimates, however, is available from the authors.

\section{REFERENCES}

Adelman, C. (2006). The toolbox revisited: Paths to degree completion from high school through college. Washington: U.S. Department of Education.

Andres, L. (1999). Investigating transfer: The student's perspective. Research report published by the British Columbia Council on Admission and Transfer website: www. bccat.bc.ca

Andres, L. (2001). Transfer from community college to university: Perspectives and experiences of British Columbia students. The Canadian Journal of Higher Education, 31(1), 35-74.

Andres, L., Qayyum, A., \& Dawson, J. (1997). Investigating transfer project phase I: Transfer experiences of students from community college to university. Retrieved from British Columbia Council on Admission and Transfer website: www.bccat.bc.ca 
Bell, S. (1998). College transfer students: A Canadian case. Community College Journal of Research and Practice, 22(1), 21.

Berger, J. B., \& Malaney, G. D. (2003). Assessing the transition of transfer students from community colleges to a university. NASPA Journal, 4O(4), 1-23.

Bers, T. H. (2007). Advancing research on the community college. Community College Review, 34(3), 170-183.

Cameron, C. (2005). Experiences of transfer students in a collaborative baccalaureate nursing program. Community College Review, 33(2), 22-44.

College University Consortium Council. (2007). Measuring the success of college transfer success at Nipissing University, 1994-2005. Retrieved from College University Consortium Council website: http://www.cucc-ontario.ca/_bin/publications/reports.cfm

College UniversityConsortium Council.(2008).Ananalysis ofundergraduatestudents admitted to York University from an Ontario college of applied arts and technology (CAAT) between 1996 and 2006. Retrieved from College University Consortium Council website: http://www.cucc-ontario.ca/_bin/publications/reports.cfm

Eggleston, L. E., \& Laanan, F. S. (2001). Making the transition to the senior institution. New Directions for Community Colleges, 114, 87-97.

Finnie, R., \& Martinello, F. (2010). I lost my scholarship": Changes in grades from high school to first year university. In R. Finnie, M. Frenette, R.E. Mueller, \& A. Sweetman (Eds.) Pursuing higher education in Canada: Economic, social, and policy dimensions (pp.15-42). Montreal \& Kingston: McGill-Queen's University Press.

Glass, J. C., \& Harrington, A. R. (2002). Academic performance of community college transfer students and "native" students at a large state university. Community College Journal of Research and Practice, 26, 415-430.

Hills, J. (1965). Transfer shock: The academic performance of the junior college transfer student. The Journal of Experimental Education, 33(3), 201-215.

Lambert-Maberly, A. (2010). Profile of BC college transfer students 2003/4 to 2007/8. Retrieved from British Columbia Council on Admission and Transfer website: www.bccat.bc.ca

Lee, V. E., \& Frank, K. A. (1990). Students' characteristics that facilitate the transfer from two-year to four-year colleges. Sociology of Education, 63(3), 178-193.

Lee, V. E., Mackie-Lewis, C., \& Marks, H. M. (1993). Persistence to the baccalaureate degree for students who transfer from community college. American Journal of Education, 63(3), 178-193.

Nolan, E. J., \& Hall, D. L. (1978). Academic performance of the community college transfer student: A five year follow up study. Journal of College Student Personnel, 19, 543-548.

Nora, A., Cabrera, A. F., Hagedon, L. S., \& Pascarella, E. T. (1996). Differential impacts of academic and social experiences on college-related behavioural outcomes across different ethnic and gender groups at four-year institutions. Research in Higher Education, 37, 427-451. 
Reason, R. D. (2003). Student variables that predict retention: Recent research and new developments. NASPA Journal, 4O(4), 172-191.

Sheldon, C. Q. (2009). Predictors of transfer to 4-year, for-profit institutions. Community College Review, 37(1), 34-51.

Thurmond, K. C. (2007). Transfer shock: Why is a term forty years old still relevant? NACADA Clearinghouse of Academic Advising Resources website: http://www.nacada. ksu.edu/Clearinghouse/AdvisingIssues/Transfer-Shock.htm

Townsend, B. K. (2001). Redefining the community college transfer mission. Community College Review, 29(2), 29-42.

Townsend, B. K. (2007). Interpreting the influence of community college attendance upon baccalaureate attainment. Community College Review, 35(2), 128-136.

Wang, X. (2009). Baccalaureate attainment and college persistence of community college transfer students at four-year institutions. Research in Higher Education, 50, $570-588$.

Wattamaniuk, W. J. (2010). Trends in the flows of transfer students from BC public colleges, institutes, and teaching intensive universities to BC public research universities. Retrieved from British Columbia Council on Admission and Transfer Website: www. bccat.bc.ca

\section{ACKNOWLEDGEMENT}

We would like to thank Gloria Gallagher, Assistant Registrar at Brock University, for her help with data collection, and Dr. Shelagh Towson for her helpful comments and suggestions.

\section{CONTACT INFORMATION}

Jo Stewart

Brock University

St. Catharines ON L2S 3A1

jstewart@brocku.ca

Having completed her education at Brock University and the University of Waterloo, Jo Stewart has a long-standing interest in student success and retention. She has published articles about academic advising and about university-college collaborations. As the Administrative Officer in the Faculty of Social Sciences, she has been involved in developing university-college transfer programs for a variety of social science disciplines. She is responsible for ensuring a seamless transfer between institutions by providing academic advice to students in these programs.

Felice Martinello was educated in economics at the University of Western Ontario and the University of British Columbia and is currently Professor of Economics at Brock University in St. Catharines, Ontario. He has written on labour unions, wage determination, and union organizing, and has recently turned his attention to post-secondary education. Recent work includes studies of faculty salaries in Ontario universities, the transitions of postsecondary students across programs and different types of institutions, and the decreases in grade levels experienced by students when they go from high school to university. 